\title{
Reviewer Acknowledgements for Vol. 5, No. 4, December 2017
}

Journal of Agricultural Studies would like to acknowledge the following reviewers for their assistance with peer review of manuscripts for this issue. Many authors, regardless of whether JAS publishes their work, appreciate the helpful feedback provided by the reviewers. Their comments and suggestions were of great help to the authors in improving the quality of their papers. Each of the reviewers listed below returned at least one review for this issue

\section{Reviewers for Volume 5, Number 4}

Abhishek A. Cukkemane, Bijasu Agri Research Laboratory LLP, India

Aftab Alam, Edenworks Inc. New York, USA

Chenlin $\mathrm{Hu}$, The Ohio State University, USA,

Ernest Baafi, CSIR-Crops Research Institute, Ghana

Ewa Moliszewska, Opole University, Poland

Gerardo Ojeda, Universidad Nacional de Colombia, Colombia

Moses Olotu, Mkwawa University College of Educati, Tanzania

Sahar Bahmani, University of Wisconsin at Parkside, USA

Zakaria Fouad Abdallah, National Research Centre, Egypt

Zhao Chen, Clemson University, USA

Zoi M. Parissi, School of Forestry and Natural Environment Aristotle University, Greece

Richard Williams,

Editor

Journal of Agricultural Studies

Macrothink Institute

5348 Vegas Dr.\#825

Las Vegas, Nevada 89108

United States

Phone: 1-702-953-1852 ext.521

Fax: 1-702-420-2900

Email: jas@macrothink.org

URL: http://jas.macrothink.org 